\section{Magnetic Resonance Imaging of Browning Development in 'Braeburn' Apple during Controlled-atmosphere Storage under High $\mathrm{CO}_{2}$}

\author{
Christopher J. Clark \\ HortResearch, Palmerston North Research Center, Private Bag 11 030, \\ Palmerston North, New Zealand
}

\section{Douglas M. Burmeister \\ HortResearch, Mt. Albert Research Center, Private Bag 92 169, Auckland, New Zealand}

\author{
Additional index words. Braeburn browning disorder, Malus $\times$ domestica, nondestructive \\ analysis, NMR
}

\begin{abstract}
Development of browning induced in 'Braeburn' apple (Malus $\times$ domestica Borkh.) fruit by a damaging $\mathrm{CO}_{2}$ concentration was monitored weekly using magnetic resonance imaging (MRI) during a 4-week storage trial $\left(0.5^{\circ} \mathrm{C}, 2 \mathrm{kPa} \mathrm{O}_{2} / 7 \mathrm{kPa} \mathrm{CO}_{2}\right)$. Discrete patches of high-intensity signal, distributed randomly throughout the fruit, were observed in multislice images of samples after 2 weeks of storage; these patches were eventually confirmed as being sites of browning reactions after dissection at the end of the trial. Subsequently (weeks 3 and 4), signal intensity at sites of incipient damage increased and patches enlarged and coalesced. After 2 weeks of storage, the extent of affected tissue, averaged across all image slices, was $1.5 \%$, increasing to $15.9 \%$ and $21.3 \%$ after 3 and 4 weeks. The average rate at which tissue damage spread in individual slices was 0.81 (range: $0-3.70) \mathrm{cm}^{2} \cdot \mathrm{d}^{-1}$ between weeks 2 and 3 , declining to 0.32 (range: $\left.0-1.55\right) \mathrm{cm}^{2} \cdot \mathrm{d}^{-1}$ in the final week. Tissue damage induced under these conditions did not spread at the same rate at all locations within individual fruit, nor was it preferentially located toward the stem or calyx ends of the fruit.
\end{abstract}

Postharvest quality of 'Braeburn' apples can be compromised by a physiological disorder known as "Braeburn browning disorder" (BBD). Symptoms associated with BBD are similar to those observed with "brownheart" in other pipfruit cultivars and include browning of the tissue throughout the cortex and core areas and formation of lens-shaped cavities, typical of $\mathrm{CO}_{2}$-induced injuries (Elgar et al., 1998; Lidster et al., 1990; Meheriuk et al., 1994). This disorder has been observed while fruit are still on the tree, and in air-stored fruit, and is exacerbated by controlled-atmosphere (CA) storage (Elgar et al., 1998; Padfield, 1975). The high skin resistance of 'Braeburn' relative to other cultivars, and thus higher internal $\mathrm{CO}_{2}$ and lower $\mathrm{O}_{2}$ levels that occur within the fruit, is a factor contributing to the disorder (Yearsley et al., 1996). However, differences in the incidence of BBD between growing regions within a season, seasonal differences, and effect of crop load and harvest maturity on BBD incidence indicate that cul-

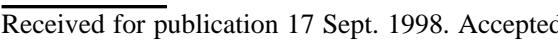
for publication $5 \mathrm{Feb}$. 1999. This study was funded by a New Zealand Foundation for Research, Science and Technology contract No. C06627. The cost of publishing this paper was defrayed in part by the payment of page charges. Under postal regulations, this paper therefore must be hereby marked advertisement solely to indicate this fact.

HortScience, Vol. 34(5), August 1999
Export-quality 'Braeburn' fruit, harvested 16 Apr. 1997, were stored at $0.5{ }^{\circ} \mathrm{C}$ for 4 weeks, commencing 20 Apr. 1997. Fruit (200$222 \mathrm{~g}$ fresh weight each) either were exposed to air throughout storage (air treatment = control), or were sealed in a 20 -L pail continuously ventilated $\left(200 \mathrm{~mL} \cdot \mathrm{min}^{-1}\right)$ with humidified gas comprising $2 \mathrm{kPa} \mathrm{O}_{2}$ and $7 \mathrm{kPa} \mathrm{CO}_{2}$ (balance $\mathrm{N}_{2}$ ).

Ten fruit were selected for MR imaging, four from the control treatment and six from the controlled-atmosphere (CA) treatment. Orthogonal lines coincident with median transverse and median longitudinal sections were lightly drawn on the surface of each fruit to facilitate alignment within the magnet, and to ensure, as far as possible, that the same image planes were selected when the same fruit were scanned at weekly intervals.

Proton $\left({ }^{1} \mathrm{H}\right)$ MR images were collected using a 1.5 Tesla Philips Gyroscan ACS-NT clinical instrument (Philips Medical Systems International, Amsterdam, Holland), and a 16.5-cm quadrature knee coil. A standard multislice Hahn spin-echo pulse sequence was employed for data collection [echo delay time $\left(\mathrm{T}_{\mathrm{E}}\right) 40 \mathrm{~ms}$; repetition time $\left(\mathrm{T}_{\mathrm{R}}\right) 1000 \mathrm{~ms}$; two acquisitions; 9-cm field-of-view; $256 \times 256$ pixel data array; 7.6-min collection time per multislice data set]. At each imaging session, nine transverse and nine longitudinal multislice images centered on median equatorial planes were obtained from every fruit. Each image slice was $4 \mathrm{~mm}$ thick, with a $2-\mathrm{mm}$ spacing between consecutive slices such that image slice centers were located 0 and $\pm 6,12,18$, and $24 \mathrm{~mm}$ from the fruit's vertical or transverse central plane (illustrated in Fig. 4). Treatment temperature and CA gas composition were not maintained during the 4-h period that fruit were out of cold storage for collection of MR data.

Datafiles (12-bit ACR-NEMA version 1.0- an industry-standard clinical imaging format) were analyzed with a public-domain software package (NIH-IMAGE ver. 1.61-available at zippy.nimh.nih.gov) using an ACRNEMA macro (ver. 1.2.1-available from fowen@spss.com) for opening the nonstandard data format on a Macintosh computer.

\section{Results}

cerning the physical and chemical environment of aqueous protons in soft tissues, such as those in fruits and vegetables (Clark et al., 1997). The technique has previously been used to monitor physiological changes associated with bruising, superficial scald, and amelioration of watercore in apple (Clark et al., 1998; Golding et al., 1997; McCarthy et al., 1995), but not browning disorders. Indeed, we did not know before experiments commenced whether symptoms could be visualized or not. Consequently, the objective of the study was to further our understanding of the development of browning disorders by using MRI to monitor internal changes in fruit stored under conditions in which a BBD-related disorder was likely to be induced (low $\mathrm{O}_{2}$ and high $\mathrm{CO}_{2}$ atmospheres).
Inspection of dissected companion samples held together with fruit in the MR treatments indicated browning development commenced after $12 \mathrm{~d}$ of CA storage (Fig. 1). The earliest indications of change occurring within MR images from CA-stored fruit were at Day 14.

Visual symptoms consistent with browning were present in each fruit in the CA treatment when MR samples were dissected after $28 \mathrm{~d}$. Comparison of MR images and photographs of the dissected fruit showed close spatial agreement between areas of high-contrast signal (light colorations), and regions of brown flesh (Fig. 2). We assumed, therefore, that the boundary between light and dark areas in MR images, which in most cases was quite 


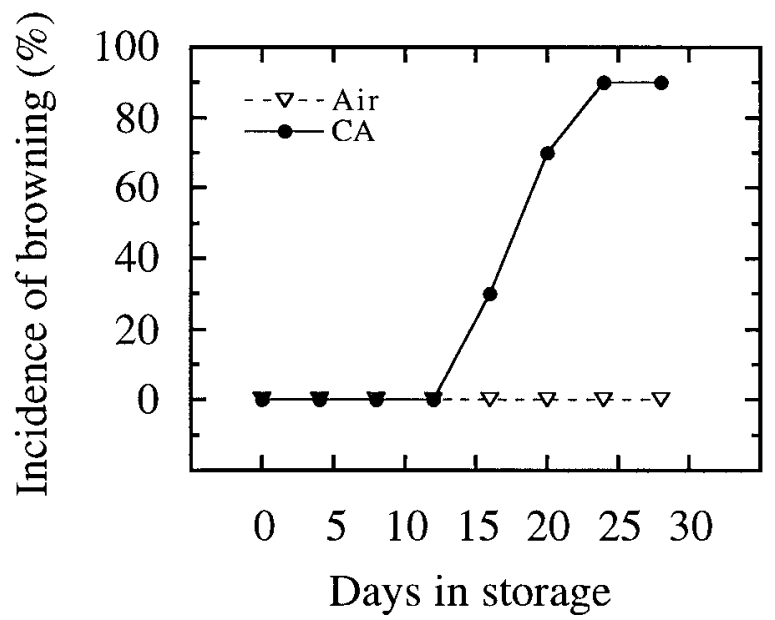

Fig. 1. Incidence of browning in companion fruit stored under the same conditions as apple fruit in the MR treatments (Air, CA). Incidence (\%) was the number of fruit in 10-fruit subsamples found to have affected tissue present when they were dissected at particular sampling times.

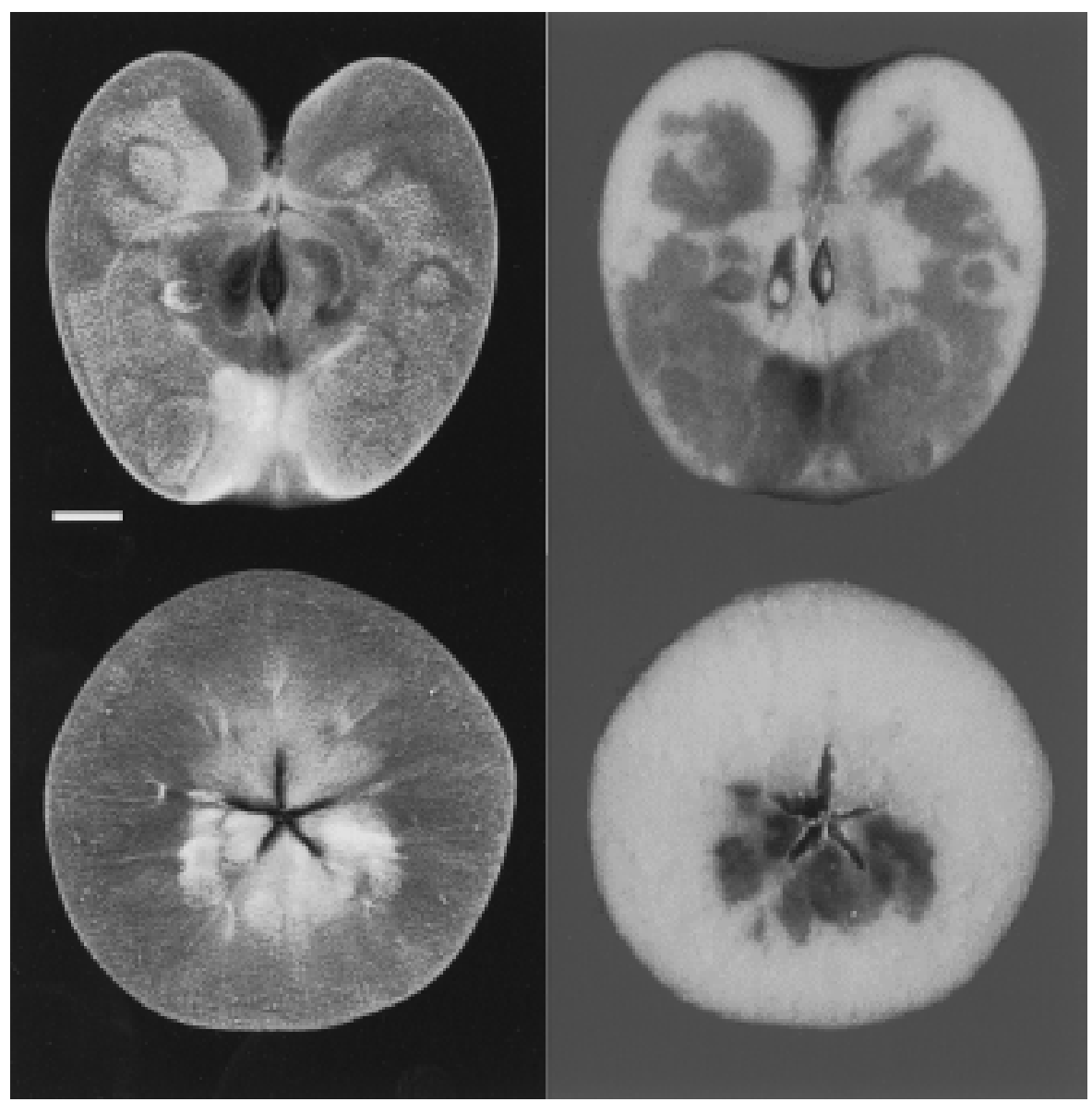

Fig. 2. Comparison of symptoms in proton MR images (left-hand column) $\left(T_{R}=1000 \mathrm{~ms} ; \mathrm{T}_{\mathrm{E}}=40 \mathrm{~ms} ; 4\right.$ mm-slice thickness; resolution $=0.35 \times 0.35 \mathrm{~mm}$ ) with photographs of the dissected apple fruit after 28 $\mathrm{d}$ of CA storage. The scale marker $(10 \mathrm{~mm})$ is applicable to each panel. The upper pair of panels is of 'Fruit 9', and the bottom pair of 'Fruit 10'. distinct, was indicative of the extent to which tissue had been affected in serial images acquired at earlier dates. In some fruit, discrete areas of flesh recorded very high signal (white) readings (Fig. 2). These were coincident with the most badly damaged, water-soaked patches of tissue in dissected fruit.

Inspection of serial image slices revealed no change in image appearance at harvest and after $7 \mathrm{~d}$ of storage. However, from Day 14 onward, discrete patches of high-contrast signal were noted, signifying changes during the previous 7-d period (Fig. 3). These patches were distributed randomly throughout the fruit, i.e., they were not confined to the stem or calyx ends, the blush or the shade side, or core vs. outer cortical tissues. At subsequent imaging sessions (Days 21 and 28), the signal intensity at sites of incipient damage increased, and patches either enlarged, or coalesced to form larger aggregates of damaged tissue (Fig. 3). By $28 \mathrm{~d}$, evidence of injury was present at some location in virtually every multislice image collected from each fruit (data not presented). In contrast, no browning or changes in image contrast were observed in any control fruits.

The distribution, extent, and rate at which tissue was affected in individual fruit was quantified in the following way. Eighteen slice planes were generated from a single apple (Fig. $4 \mathrm{a}$ and b). Within each individual image, the total area inside the fruit circumference (including locule cavities) was determined automatically by an "edge detection" technique. The area occupied by any locule cavities was similarly detected and subtracted from the total to give the area of flesh alone. Affected tissue was measured by manually tracing around light/dark boundaries using a drawing tool and allowing the program to determine the area within the inscribed boundary. Examples of the boundaries produced by this approach for a transverse slice and a longitudinal slice appear in Fig. $4 \mathrm{c}$ and d. This procedure worked well for all fruit except one in which, at 21 and $28 \mathrm{~d}$ after harvest, nearly all the tissue in median slices was affected and we could not determine where the affected/unaffected boundaries should be located. Data from this fruit were not included in the summary statistics that follow. Affected tissue was subsequently expressed as a percentage of the area of flesh present and graphed with respect to distance from the center of the fruit (Fig. 5).

After $14 \mathrm{~d}$ of storage, the extent of affected tissue, averaged across all image slices in either transverse or longitudinal data sets $(n=$ 54: six fruit $\times$ nine slices from each fruit in either plane) was $1.5 \%$ (Fig. 5). This increased to $15.9 \%$ and $21.3 \%$ after 21 and $28 \mathrm{~d}$, respectively. The greatest proportion of affected tissue present in a single image slice after $14 \mathrm{~d}$ was $10.5 \%$. This rose to $80.8 \%$ at $21 \mathrm{~d}$, and $86.8 \%$ at the conclusion of the study. The average rate at which tissue damage spread was $0.81(0-3.70) \mathrm{cm}^{2} \cdot \mathrm{d}^{-1}$ between Days 14 and 21 , declining to $0.32(0-1.55) \mathrm{cm}^{2} \cdot \mathrm{d}^{-1}$ during the final week. Values in parenthesis represent the range of daily rates determined from individual slices.

HortScience, Vol. 34(5), August 1999 


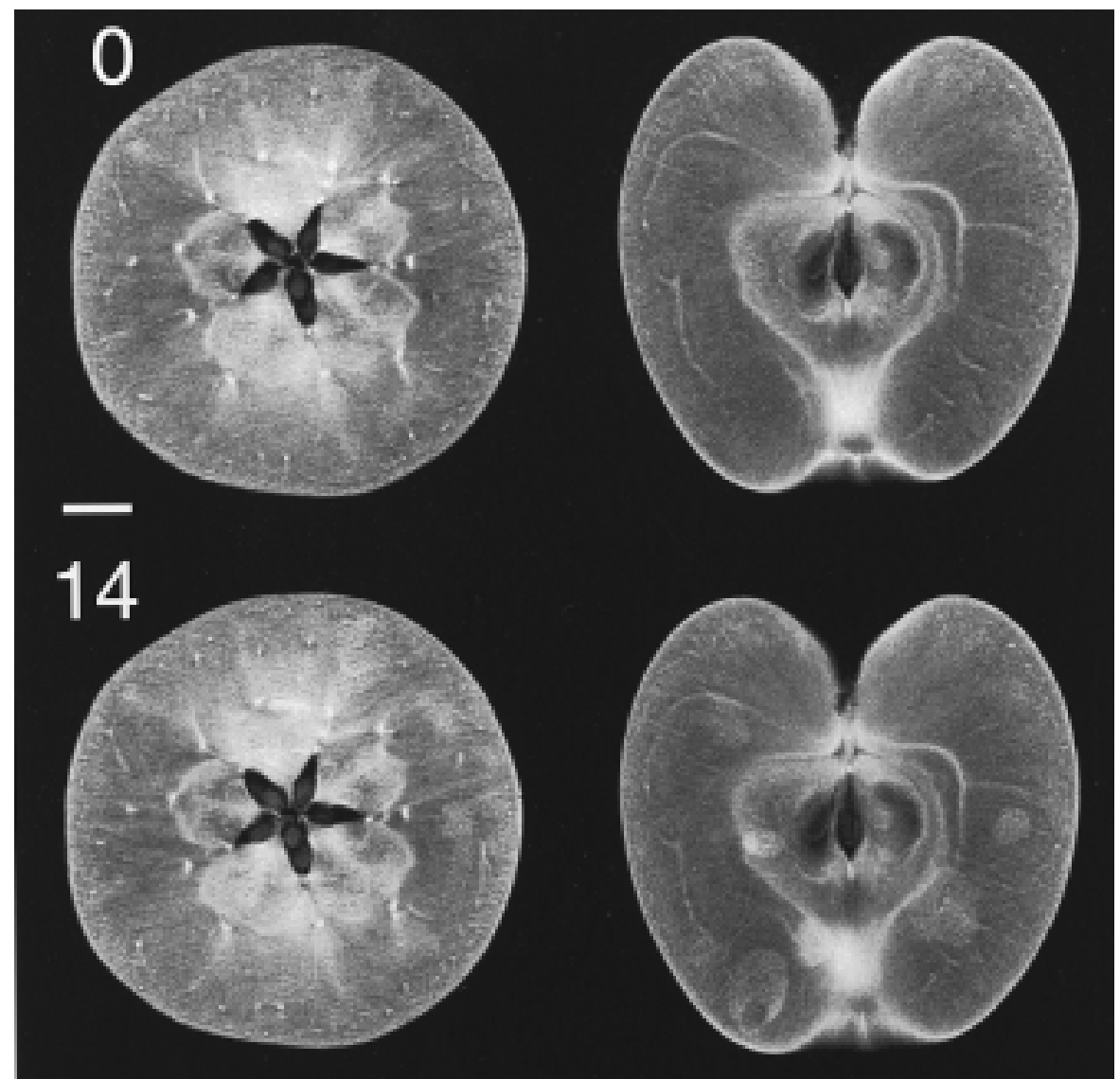

Overall, this data set identified the third week of storage as being the period during which the greatest amount of damage occurred. Furthermore, it indicated that damage did not spread at the same rate at all locations within individual fruit, nor was there a tendency for affected tissue to be located preferentially at either the stem or calyx ends of the fruit (Fig. 5; transverse-slices). While there was clearly an effect of "side" in the distribution of affected tissue in longitudinal images slices (Fig. 5), this could not be linked to a shade/blush orientation of fruit.

There are several discrepancies between the results noted here and symptoms of BBD. For example, cavity formation in affected flesh was absent in all fruit kept in CA. Similarly, our observation that the first evidence of browning reactions occurred at sites randomly distributed throughout the fruit contradicts anecdotal information (J. Elgar, personal communication) that BBD development occurs initially toward the calyx end of the fruit. This is not surprising. Under the conditions of this investigation, a high $\mathrm{CO}_{2}$ concentration $(7 \mathrm{kPa}$ $\mathrm{CO}_{2}$ ) was deliberately employed to guarantee that browning reactions would be induced quickly. Conditions during commercial storage when 'Braeburn' exhibits BBD are $2 \mathrm{kPa}$ $\mathrm{O}_{2} / 1 \mathrm{kPaCO}_{2}$, and the period for injury development is much longer. So although we have duplicated certain of the features associated with $\mathrm{BBD}$, our results are pertinent to a more generalized treatment of the development of browning reactions rather than those associated with a specific disorder.

\section{Discussion}

This is the first report on development of a browning disorder using MRI. Satisfactory agreement between the appearance of MR image slices and cut sections of the same fruit, and between the time when visible symptoms were first observed in serial images (Day 14) and dissected companion fruit (Day 16), indicates that MR imaging can be used to investigate browning disorders in a range of experimental situations where there is a high probability that the disorder can be induced.

The images themselves contain detailed information concerning physiological changes. However, because of the complex manner in which the MR signal arises (Clark et al., 1997), their interpretation is open to question. For example, in the $\mathrm{T}_{1}$-weighted images here (Fig. $3), T_{1}$ being the unique nuclear magnetic resonance (NMR) parameter describing the interaction between nuclear spins and their surrounding environment (spin-lattice relaxation), light regions within an image (high signal intensity) may signify proton populations that are motionally restricted, perhaps by association with proteins or lipids, and hence relax very quickly (short $\mathrm{T}_{1}$ times). Conversely, protons in less restricted environments, such as free water, have longer $\mathrm{T}_{1}$ times and are seen as darker parts of the image. Classical NMR theory indicates that variation in relaxation rates may also be rationalized in terms of differences in solution properties such as vis-

Fig. 3. Serial images of the development of symptoms in median equatorial slices (transverse and longitudinal) of apple 'Fruit 9', after 0, 14, 21, and $28 \mathrm{~d}$ of CA storage. Scale marker $=10 \mathrm{~mm}$. Details of the proton MR image parameters are the same as in Fig. 2. 


\section{Postharvest Biology \& Technology}

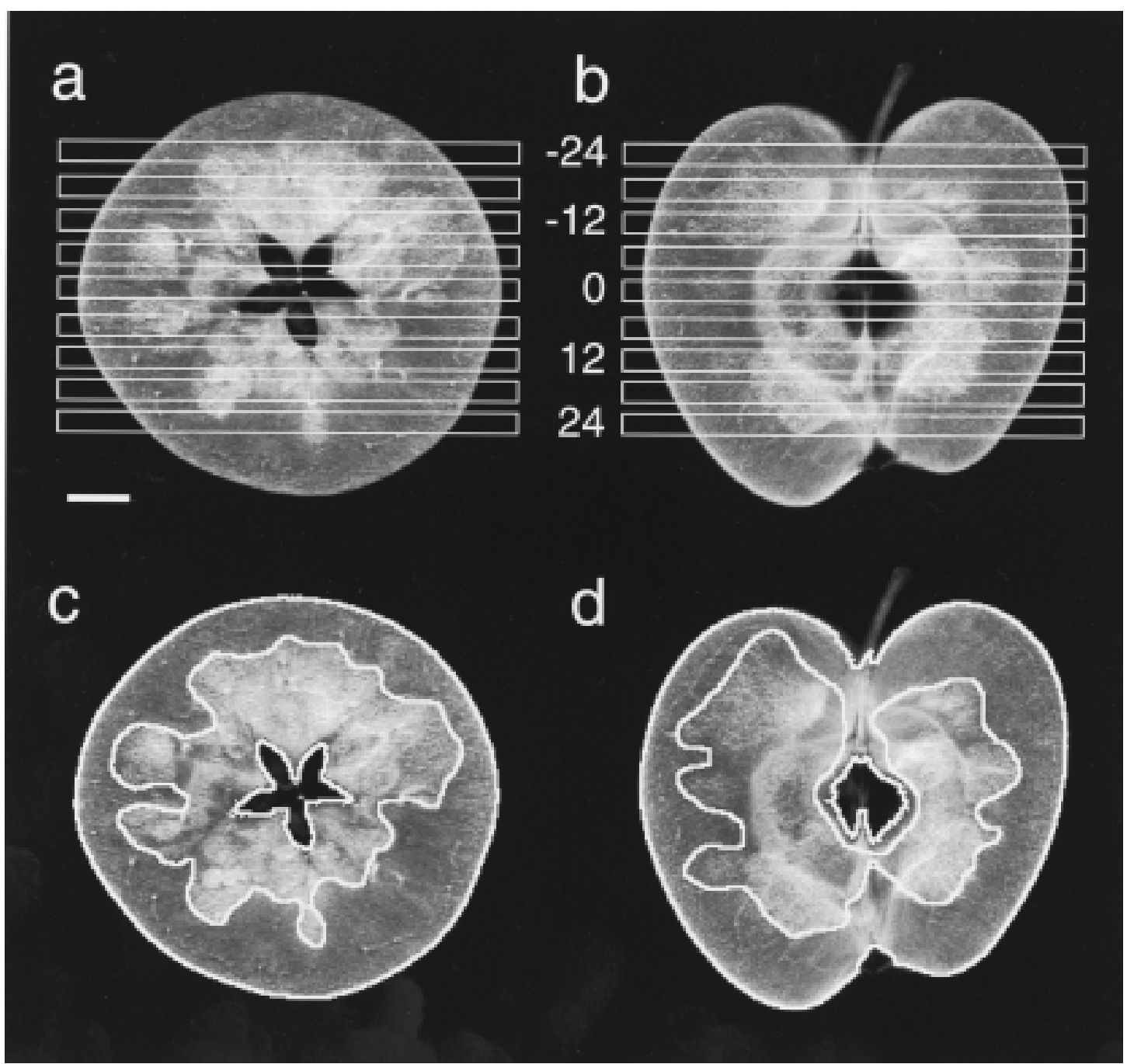

Fig. 4. Image slices of the (a) transverse and (b) longitudinal equatorial plane of apple 'Fruit 5'. Rectangular overlays indicate the thickness (4 mm) and location of the nine orthogonal slice planes from which data were obtained to describe the extent and distribution of affected tissue (Fig. 5). Numbers (in mm) describe the location of the centre of the slice planes with respect to the center of the apple fruit. Boundaries in images (c) and (d) are indicative of those generated by edge detection techniques (circumference and locule cavities) and drawing tools (affected tissue) in the procedure quantifying the percentage of area affected in individual images. Scale marker $=10 \mathrm{~mm}$.

cosity and composition (Bloembergen et al., 1948). Nevertheless, interpretation of image contrast can still be confounded by contributions from proton density if the water content of individual tissues differs or changes over time. Thus, one could describe the areas associated with spreading brown tissue as locations in which the $T_{1}$ relaxation rate becomes faster relative to unaffected tissue, and that this is attributable to increased, localized concentrations of respiratory metabolites such as organic acids, acetaldehyde, and ethanol (Kennedy et al., 1992).

Despite the qualitative nature of the present investigation, the images raise intriguing questions. What predisposes particular locations within the fruit to be the first to develop symptoms? The location affected did not appear to be consistent nor was it confined to the outer cortex. And does imaging detect sites of incipient breakdown before they can be observed visually, when browning reactions have already taken place? There are a range of pulse sequence experiments beyond that used here that are capable of producing calculated "maps" (images) of the individual contributions that relaxation parameters $\left(\mathrm{T}_{1}\right.$ and $\left.\mathrm{T}_{2}\right)$ and proton density confer on image intensity. This is referred to as Quantitative Imaging (Clark et al., 1997). Still other sequences allow the localized diffusive properties of water to be determined in vivo. Future investigations of BBD and browning disorders that include these experiments, as well as detailed studies of the biochemistry at sites of browning tissue, should provide a more comprehensive picture of the physiology of these processes. In terms of online detection of fruits with browning disorders, there are as yet no commercial applications in which NMR techniques are being used to segregate fruit with different internal properties, although a number of applications have been demonstrated experimentally (Clark et al., 1997). Nondestructive, lower cost alterna- tives to imaging exist, but for techniques such as light transmittance, the ability to detect internal browning on-line remains a challenge (Upchurch et al., 1994).

\section{Literature Cited}

Bloembergen, N., E.M. Purcell, and R.V. Pound. 1948. Relaxation effects in nuclear magnetic resonance absorption. Phys. Rev. 73:679-712.

Clark, C.J., P.D. Hockings, D.C. Joyce, and R.A. Mazucco. 1997. Application of magnetic resonance imaging to pre- and postharvest studies of fruits and vegetables. Postharvest Biol. Technol. 11:1-21.

Clark, C.J., J.S. MacFall, and R.L. Bieleski. 1998 Amelioration of watercore in 'Fuji' apple observed by magnetic resonance imaging. Scientia Hort. 73:213-227.

Elgar, H.J., D.M. Burmeister, and C.B. Watkins. 1998. Storage and handling effects on a $\mathrm{CO}_{2}$ related internal browning disorder of 'Braeburn' apples. HortScience 33:719-722.

Golding, J.B., V. Sarafis, S. Crozier, and S.E. Rose. 

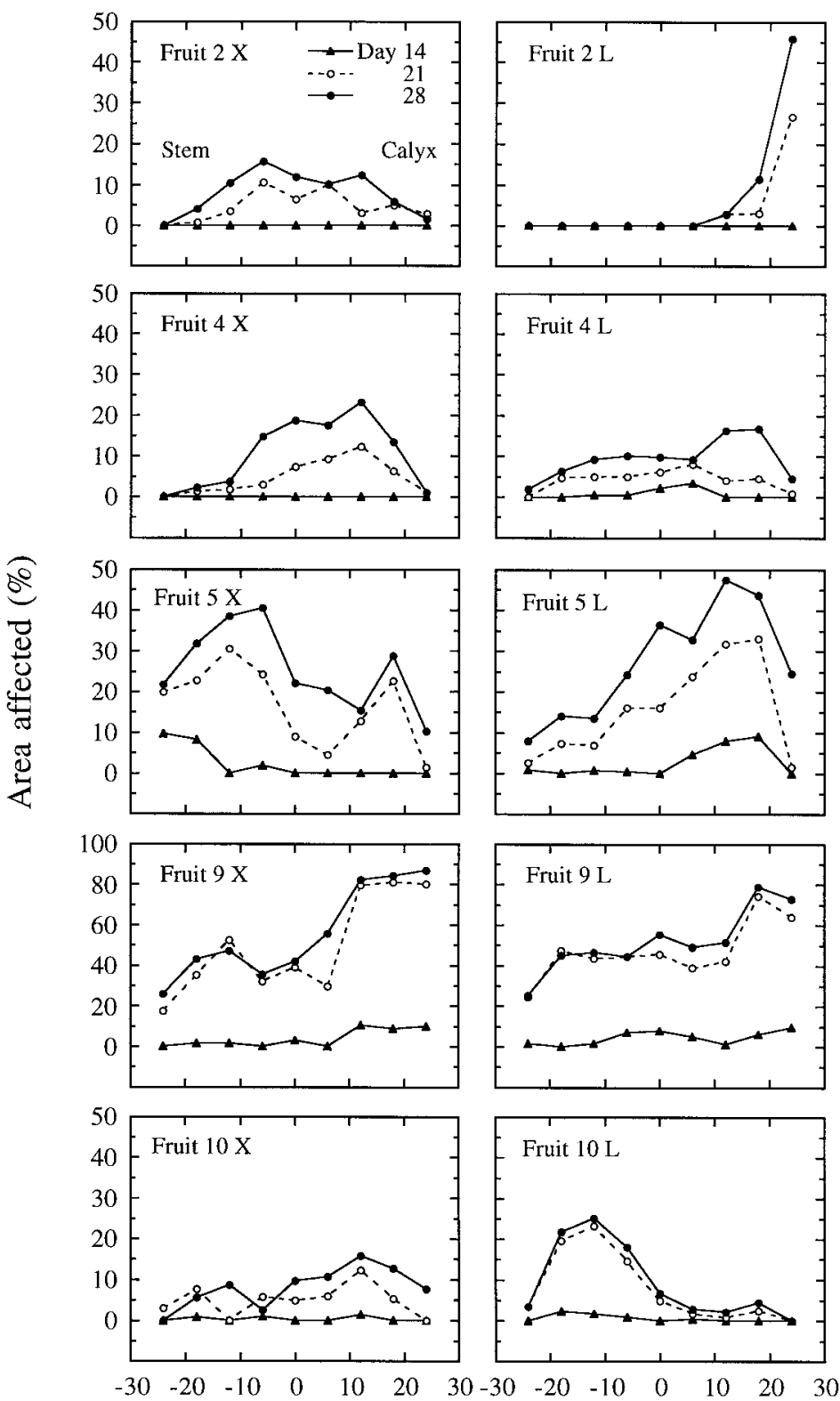

Distance from center (mm)
1997. Nuclear magnetic resonance imaging of superficial scald in 'Granny Smith' apples. HortScience 32:112-113.

Kennedy, R.A., M.E. Rumpho, and T.C. Cox. 1992. Anaerobic metabolism in plants. Plant Physiol. 100:1-6.

Lau, O. 1998. Effect of growing season, harvest maturity, waxing, low $\mathrm{O}_{2}$ and elevated $\mathrm{CO}_{2}$ on flesh browning disorders in 'Braeburn' apples. Postharvest Biol. Technol. 14:131-141.

Lidster, P.D., G.D. Blanpied, and R.K. Prange. 1990. Controlled-atmosphere disorders of commercial fruits and vegetables. Agr. Can. Publ. 1847/E. p. 7-11; 15-18.

McCarthy, M.J., B. Zion, P. Chen, S. Ablett, A.H. Darke, and P.J. Lillford. 1995. Diamagnetic susceptibility change in apple tissue after bruising. J. Sci. Food Agr. 67:13-20.

Meheriuk, M., R.K. Prange, P.D. Lidster, and S.W. Porritt. 1994. Postharvest disorders of apples and pears. Agr. Can. Publ. 1737/E. p. 18-21;2427. (Revised 1982 printing.)

Padfield, C.A.S. 1975. Storage conditions for some of the more recently introduced apple cultivars. Orchardist N.Z. 48:64.

Upchurch, B.L., J.A. Throop, and D.J. Aneshansley. 1994. Detection of internal browning in apples by light transmittance. Proc. Soc. Photo-Optical Instrum. Eng. 2345:377-384.

Yearsley, C.W., N.H. Banks, S. Ganesh, and D.J. Cleland. 1996. Determination of lower oxygen limits for apple fruit. Postharvest Biol. Technol. 8:95-109.

Fig. 5. Temporal change in the extent and distribution of affected tissue after 14, 21, and $28 \mathrm{~d}$ of CA storage in individual apple fruit. Note: symptoms were not observed in images prior to Day 14. For transverse sections (labeled $X$ in the lefthand column) negative numbers on the $\mathrm{x}$-axis are toward the stem end of the fruit. Axis labelling is arbitrary for longitudinal (L) section data. Each datum point represents a measurement from a single slice (as in Figs. 3 and 4). 